\title{
The social role of research in nursing
}

\author{
Jussara Gue Martini
}

REBEn's Scientific Editor and ABEn's Director of Publication and Social Communication Board for the 2007-20I0 period

In the construction of its ways, and in the search for a social meaning, Nursing tries to keep distant of health-related areas, changing its world reading referential, reorganizing the education processes, reorienting its knowledge and practice, elaborating theory based on new paradigms, experiencing the new.

In nowadays complex society, although all the achievement and improvements of digital networks and of population growing levels of access to information, the advances toward the generation of an information system that work as a tool of critical and innovative thinking, the achieved benefits in the production of new manners of caring have been Questionable.

Thus, one of goals of the knowledge production and dissemination is to reflect about the potential output from an informatics functionalist model and a move toward the manners of doing nursing with the potentiality for constructing a technical and scientific language that contributes to minimize the social inequalities, and not only to reproduce them. Such decision implies in becoming visible in the different power spaces that defeat the knowledge by preventing the reinvention of collective systems of empowerment.

Perhaps, the alternative is to examine the path evidencing the limits and potentialities of each action. The production and dissemination of knowledge as fundamental aspects for innovation need to be developed with a social, politic, and scientific commitment.

Although more than $80 \%$ of labor is engaged in local market and also a major part of resources does not circulate in a global perspective, our production is directed to connections in global networks, in a such way that our knowledge depend on working dynamics of given "scientific central core". In this process information occupies a central position, offering technology that ensures the interconnection of several elements, people, and processes that make the knowledge society.

However, the decentralization, the flexibility, and the velocity that characterizes our society does not lead to democratization, but unlike lead us to an implosion of centralization, to an unprecedented concentration of decision power. Information and technology by themselves do not lead to concentration, but their determinant logic is the private productivity, empty of integrative content.

Thus, knowledge produces, spreads, and provides the material base for a symbolic universe in health, as a bearer of sensibility and a matrix of social abilities. This recalls us to focus in the obscuration, legitimating and industrialization of memory, therefore, currently the literal memory of books and texts is substituted by analogical and memories and the critical work even is not necessary when the codification and decodification is delegated to machines, what provokes a memory industrialization, a pausterized knowledge, distant of comparison, reflection a historic-social evaluation.

In this way, the control over the rhythms acceleration in information production is lost, the integral knowledge is impoverished, and the critical thinking is ruptured.

Information is a political toll of scientific discourse and its contraposition expresses the interest in games of political scenario. The operational concepts and terms with hegemonic position in a given scientific area is constructed as responses to pressures and are docked to needs and benefits of those who have the power in sustaining them. The paradigms and codes used rise and develop in concrete socio-cultural environments where some ideas are possible and valuable.

The amplification of translation and transferring of knowledge in linear networks connected to civil society constitutes a welfare that grows as it is used and decreases as it is not used. In general, the knowledge must stimulate cooperation, to be produced in interaction and interconnection to social needs, seeking a better information flow and confidence between the social actors. In health case, the aim is the welfare promotion for the population.

Such reflections aim for urgency in the appropriation in the debate about what information, what science do we desire to leave for the next century. Will we prioritize the volume, the dissemination as an end in itself? Or, on the contrary, will we resist in the move of testing research lines based on the responsibility of constructing content and processes that express the need for a sustainable multicultural care of our time? 